\title{
PRINCIPAIS ASPECTOS CONSIDERADOS POR CONSUMIDORES NA AQUISIÇÃO E CONSUMO DE CARNE SUÍNA EM COLÔNIA DO PIAUÍ-PI
}

\author{
Aracele Prates de Oliveira ${ }^{1}$ \\ Crenilde Pachêco da Silva ${ }^{2}$ \\ Hermógenes Almeida de Santana Júnior ${ }^{2}$ \\ Maurílio Souza dos Santos ${ }^{2}$ \\ Johnny Martins de Brito \\ Fabrício Bacelar Lima Mendes ${ }^{1}$ \\ Elizângela Oliveira Cardoso Santana ${ }^{2}$
}

OLIVEIRA, A. P. de; SILVA, C. P. da; SANTANA JÚNIOR, H. A. de; SANTOS, M. S. dos; BRITO, J. M. de; MENDES, F. B. L.; SANTANA, E. O. C. Principais aspectos considerados por consumidores na aquisição e consumo de carne suína em Colônia do Piauí-PI. Arq. Ciênc. Vet. Zool. UNIPAR, Umuarama, v. 20, n. 2, p. 71-77, abr./jun. 2017.

RESUMO: Objetivou-se avaliar o perfil do consumidor, da carne suína, quanto aos aspectos importantes considerados para o consumo, na cidade de Colônia do Piauí-PI. A pesquisa foi feita em forma de questionários com perguntas objetivas, sendo abordados nas residências da cidade, no interior e também nos estabelecimentos comerciais. As informações coletadas foram processadas pelo programa computacional Excel ${ }^{\circledR}$. Foram entrevistadas 100 pessoas, sendo $38 \%$ homens e $62 \%$ mulheres. Constatou-se que $95 \%$ dos entrevistados consomem a carne suína, dando preferência a carne bovina citada por $42 \%$. A maior frequência de consumo da carne suína foi considerada mensalmente por $36 \%$ dos entrevistados. Na região, $77 \%$ dos entrevistados consomem a carne suína mais sobre a forma in natura apresentando maior preferência pelo corte cárneo, costela com 35,8\% dos consumidores e dentre os industrializados a linguiça liderou em consumo (48\%). Possibilitou-se verificar que $86 \%$ afirmaram nunca ter visualizado propaganda de incentivo ao consumo de carne suína. Os entrevistados acreditam que os animais que passam menor desconforto na produção e no abate são as aves e peixes, ambos com 37\% das opiniões. Percebe-se que o principal entrave para consumo da carne suína em Colônia do Piauí-PI pode estar atrelado à falta de esclarecimento sobre os benefícios de que a carne suína pode trazer, e de investimentos em marketing que desmistifiquem os problemas relacionados às questões sanitárias e ao teor de gordura. A frequência de consumo pode ser aumentada, já que o preço não foi o fator limitante para o consumo.

PALAVRAS-CHAVE: Frequência. Perfil de consumo. Preferência. Qualidade da carne suína.

\section{KEY ASPECTS CONSIDERED BY CONSUMERS IN THE PURCHASE AND CONSUMPTION OF PORK IN COLÔNIA DO PIAUÍ-PI}

\begin{abstract}
The purpose of this study was to assess the profile of pork consumers regarding key aspects considered for the consumption in Colônia do Piauí - PI. The survey was developed through questionnaires containing closed-end questions applied to residents at their homes and also at stores in the city. The data were processed using Microsoft Excel ${ }^{\circledR}$. A total of 100 people were interviewed, being 38\% men and 62\% women. The results showed that $95 \%$ of the respondents consume pork, although $42 \%$ preferred beef. The highest frequency of pork consumption was considered on a monthly basis by $36 \%$ of the respondents. In the region, $77 \%$ of the respondents consume pork mostly in natura, expressing preference for pork rib cuts, with $35.8 \%$ of consumers; sausage was the most frequently consumed item among industrialized goods, with $48 \%$. The main reason for not consuming pork more often was the idea that the meat had high cholesterol levels, answer provided by $55.8 \%$ of the respondents. It was also possible to verify that $86 \%$ said they had never viewed any advertising encouraging the consumption of pork. Respondents believe that animals that provide the lowest levels of discomfort in the production and slaughter are birds and fish, both with $37 \%$ of the answers. It can be concluded that the main obstacle to the consumption of pork in Colônia do Piauí - PI may be linked to a lack of awareness about the benefits pork can bring, and of marketing investments to clarify the sanitary and fat content issues. The consumption frequency can be increased, since price was not the limiting factor for consumption.
\end{abstract}

KEYWORDS: Consumption profile. Frequency. Pork quality. Preference.

\section{PRINCIPALES ASPECTOS CONSIDERADOS POR CONSUMIDORES EN LA ADQUISICIÓN Y CONSUMO DE CARNE PORCINA EN LA CIUDAD DE COLONIA DEL PIAUÍ-PIAUÍ}

RESUMEN: Se ha buscado evaluar el perfil del consumidor de la carne porcina, en cuanto a los aspectos importantes considerados para el consumo, en la ciudad de Colonia del Piauí - Piauí. La investigación se hizo en forma de cuestionarios

\footnotetext{
DOI: 10.25110 /arqvet.v20i2.2017.5810

${ }^{1}$ Pesquisadora da Fundação de Amparo a Pesquisa do Estado do Piauí- FAPEPI/Programa de Desenvolvimento Científico Regional - DCR.

Email: araceleprates@hotmail.com

${ }^{2}$ Universidade Estadual do Piauí

${ }^{3}$ Doutorando, Universidade Estadual de Maringá, UEM.
} 
con preguntas objetivas, siendo abordados en las residencias de la ciudad, en el interior y también en los establecimientos comerciales. Las informaciones recopiladas fueron procesadas por el programa computacional Excel®. Se entrevistó a 100 personas, siendo $38 \%$ hombres y $62 \%$ mujeres. Se constató que el $95 \%$ de los entrevistados consumen la carne porcina, dando preferencia a la carne bovina citada por el $42 \%$. La mayor frecuencia de consumo de la carne de cerdo fue considerada mensualmente por el 36\% de los entrevistados. En la región, el $77 \%$ de los entrevistados consumen la carne porcina más sobre la forma in natura presentando mayor preferencia por el corte cárneo, costilla con 35,8\% de los consumidores y entre los industrializados la longaniza lideró en consumo (48\%). Se pudo verificar que el $86 \%$ afirmaron nunca haber visto propaganda de incentivo al consumo de carne porcina. Los entrevistados creen que los animales que pasan menos molestias en la producción y en el sacrificio son las aves y los peces, ambos con el 37\% de las opiniones. Se percibe que el principal obstáculo para el consumo de carne de cerdo en Colonia del Piauí-PI puede estar vinculado a la falta de aclaración sobre los beneficios de que la carne de cerdo puede traer, y de inversiones en marketing que desmistifiquen los problemas relacionados con las cuestiones sanitarias y al contenido de grasa. La frecuencia de consumo puede ser aumentada, ya que el precio no fue el factor limitante para el consumo.

PALABRAS CLAVE: Frecuencia. Perfil de consumo. Preferencia. Calidad de la carne porcina.

\section{Introdução}

A produção de suínos evoluiu muito nos últimos anos, devido a avanços no melhoramento genético, nutrição e sanidade, de modo que o alto padrão da carne suína é proveniente de animais precoces, eficientes e que apresentam carcaças com elevada relação carne: gordura está associada a um ótimo padrão de qualidade e de segurança dos alimentos comparáveis ou superiores a outras carnes (BERTOL et al., 2010; SILVA et al., 2015).

A carne suína é a proteína de origem animal mais consumida no mundo e sua qualidade no mercado tem importância em todos os segmentos industriais, ultrapassado a preferência dos consumidores por outras carnes desde o ano de 1979 (MUNIZ et al., 2015). Nos últimos anos a carne suína vem passando por transformações na produção, deixando de ser uma atividade familiar, proporcionando uma nova imagem aos consumidores de uma carne magra, saudável, rica em nutrientes e proporcionando benefícios a saúde (SALES et al., 2013).

O Brasil possui mercado interno com grande potencial para o consumo desta carne, sendo $74 \%$ consumido internamente e $26 \%$ exportado (SIMÕES et al., 2012).

Segundo Simões et al. (2012) um dos pontos determinantes para o aumento do consumo de carne suína está na necessidade de garantir que o produto atenda às expectativas dos consumidores. Para tanto, é importante que todos os envolvidos na cadeia produtiva conheçam os atributos de qualidade que os consumidores buscam, apresentando atributos que os consumidores desconheçam. Segundo as projeções apresentadas por Souza et al. (2011), o consumo brasileiro de carne suína passará de 2,7 milhões de toneladas em 2010 para 3,2 milhões de toneladas em 2020, correspondendo a um aumento anual de $1,8 \%$.

De acordo com Muniz et al. (2015) o consumo de carne suína entre os brasileiros ainda é baixo, estando muitas vezes atrelado ao preconceito devido à falta de informação sobre a mudança da suinocultura brasileira e por acreditarem que a carne suína apresenta alto teor de gordura e que faz mal a saúde.

Ao avaliar o comportamento dos consumidores compreendem-se as preocupações de se obter alimentos seguros e com qualidade. Além de identificar e analisar o comportamento de compra dos consumidores com o intuito de melhor satisfazer as suas necessidades.

Necessitando de estratégias de marketing, para que venha a passar confiança aos consumidores, afastando os preconceitos que estão atrelados a carne suína, para que as gerações futuras melhorem seu conceito sobre a carne suína. $\mathrm{O}$ interesse atual dos consumidores não se limita apenas às características da carne, mas também às condições de sanidade e bem-estar nas quais os animais são criados.

Objetivou-se avaliar o perfil do consumidor, de carne suína, quanto aos aspectos importantes considerados para o consumo, na cidade de Colônia do Piauí-PI.

\section{Material e Métodos}

A pesquisa foi realizada na cidade de Colônia do Piauí-PIno período compreendido entre 22 de dezembro de 2014 a 08 de janeiro de 2015. Este estudo foi realizado após aprovação do Comitê de Ética em Pesquisa (CEP) da Universidade Estadual do Piauí (UESPI), caso n. 012/16.

A cidade de Colônia do Piauí-PI fica localizada no Piauí possuindo uma área de 963,5 km², "Latitude: $07^{\circ} 13$ ' 52" S Longitude: $42^{\circ} 10$ ' 41 “W, possui 7.433 habitantes conforme a fonte do censo do Instituto Brasileiro de Geografia e Estatística (IBGE, 2013).

Foi realizada uma pesquisa em forma de questionário com perguntas objetivas, os entrevistados foram abordados em residências na zona urbana, rural e também em estabelecimentos comerciais, com intuito de averiguar a o perfil e consumo dos consumidores.

Foram entrevistados 100 indivíduos, escolhidos de forma aleatória, o questionário apresentava-se com 20 questões objetivas com duas a cinco alternativas cada questão.

A análise dos dados foi realizada através da estatística descritiva através do programa Microsoft ${ }^{\circledR}$ Office Excel 2010. Os resultados, plotagem dos gráficos e tabelas foram obtidos utilizando planilha eletrônica e expressos em percentagem utilizando o programa Microsoft ${ }^{\circledR}$ Office Excel 2010.

\section{Resultados e Discussão}

A carne suína é uma das mais apreciadas segundo a opinião dos consumidores, mas ficou em terceiro lugar na preferência geral. Foram entrevistadas 100 pessoas, das quais trinta e oito por cento (38\%) eram do sexo masculino e sessenta e dois por cento (62\%) do sexo feminino.

A presente pesquisa revelou que no que se refere à espécie de carne mais consumida, verificou-se a preferência dos consumidores pela carne bovina com $42 \%$ das citações, 
seguida de aves $22 \%$ e em terceiro lugar a de suínos com 15\% (Figura 1). Thoms et al. (2010), Farias et al. (2012), Silva et al. (2014), Taffarel et al. (2013) e Nantes et al. (2014) também verificaram, através de pesquisas em regiões brasileiras diferentes (PR, PB, GO e MG) que a carne bovina é a preferida, seguida de aves e terceira a suína.

A falta de informação é o maior obstáculo para a aquisição e consumo da carne suína na maioria das regiões brasileiras. Conceitos errôneos sobre a carne suína causam impactos negativos na sociedade, fazendo com que a mesma seja vista como uma "carne gorda, que faz mal a saúde e que pode transmitir doenças".

Santos et al. (2012) relatam que a carne suína é um alimento com alto valor nutritivo e saboroso, rica em vitaminas e minerais, indispensável à mesa do consumidor. Antes era conhecida como uma carne "gorda" e "forte" passando a ser uma carne magra e mais saudável.

Figura 1: Tipo de carne mais consumida pelos entrevistados em Colônia do Piauí-PI.

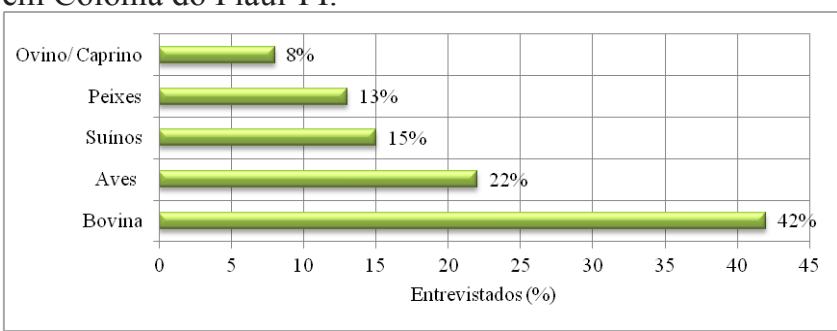

Verificou-se que a maioria dos consumidores de carne suína desconhece as qualidades nutricionais da mesma, quando questionados sobre quais carnes possuem menor quantidade colesterol, a maioria $84 \%$ respondeu ser o peito de frango seguido pela alcatra bovina e o filé mignon bovino ambos com 8\% das opiniões (Figura 2).

Mesmo estando inserido na questão, o lombo suíno não foi mencionado pelos entrevistados, isso pode ser pela falta de esclarecimento de que a carne suína tem níveis de gordura e colesterol semelhantes ou até mais baixos do que os demais cortes cárneos.

Hautrive et al. (2012) encontraram menores quantidade de colesterol na carne suína, quando comparada com as outras carnes. Antonangelo et al. (2011) constataram que se for retirada toda a camada externa de gordura, a carne suína apresentará teores de gordura semelhante ao da carne de frango.

Figura 2: Cortes cárneos com menor quantidade de colesterol segundo os entrevistados em Colônia do Piauí-PI.

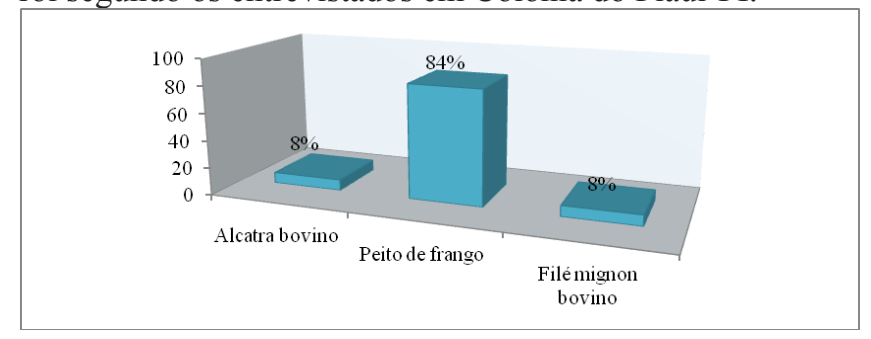

Foi possivel observar que $74 \%$ dos entrevistados responderam que a carne suína possui o maior nível de transmissão de doenças (Figura 3). Farias et al. (2012) e Silva \&
Silva (2009) relataram em suas pesquisas, que a maioria entrevistada afirma ter a informação de que a carne suína pode trazer algum risco para saúde humana. Santos et al. (2012) enfatizam que conceitos errados são transmitidos de geração a geração e ainda são reforçadas pelos médicos, consistindo na opinião da maioria da população.

Figura 3: Risco de transmissão de doenças dos diferentes tipos cárneos segundo os entrevistados em Colônia do Piauí-PI.

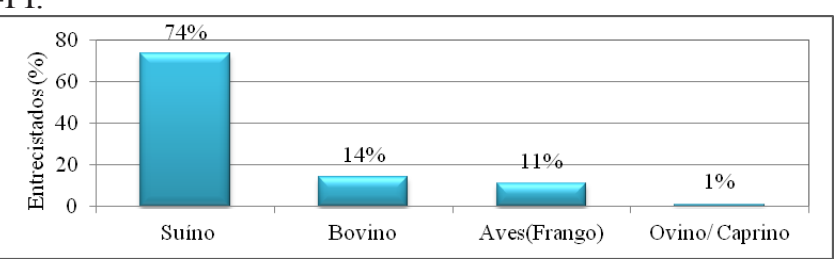

Dentre os sistemas de criação que causam menor desconforto na produção e no abate dos animais, os entrevistados acreditam que todos os animais passam por algum tipo de desconforto. Embora não conheça o tipo correto de abate só o mais rústico e produção extensiva, $37 \%$ consideram serem os peixes e as aves seguidos pelos suínos e cordeiros com $10 \%$ (Figura 4 ) a passarem por menor desconforto durante o abate.

Segundo Baptista, Bertani e Barbosa, (2011) a busca da sociedade e do mercado externo por produtos éticos e de qualidade tem conquistado alguns progressos na produção de animais, o que torna necessário estabelecer critérios que avaliem o bem-estar dos animais em seus sistemas de criação. Raineri et al. (2012) destacam que a falta de informação é a maior barreira para a aquisição e consumo de produtos diferenciados em termos de bem-estar.

Figura 4: Menor desconforto na produção e abate dos animais segundo os entrevistados em Colônia do Piauí-PI.

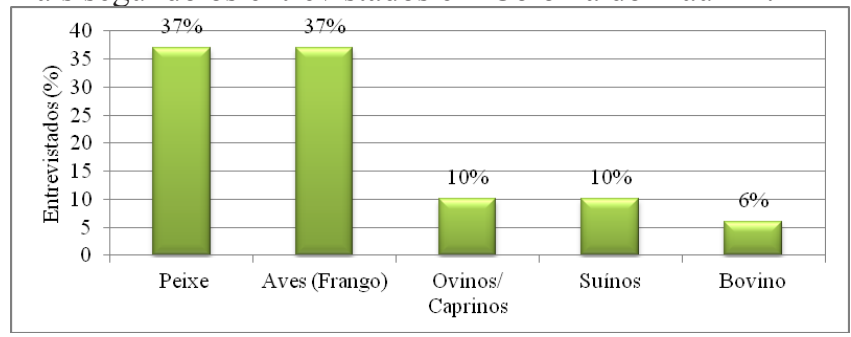

A respeito de propagandas que desmistifiquem os conceitos e que desfaçam a falsa imagem atribuída a carne suína de que é uma alimentação "vilã" e estimulem o seu consumo, $86 \%$ dos entrevistados disseram nunca ter visto propaganda de incentivo ao seu consumo (Figura 5).

De acordo com os dados coletados por Antonangelo et al. (2011) sobre o conhecimento de propagandas que desfaçam a falsa imagem atribuída à carne suína e que incentive o consumo,a maioria de seus entrevistados nunca viram nada do tipo.

Segundo Taffarel et al. (2013) a mudança dessa imagem requer investimentos em marketing, que englobe toda a cadeia produtiva da carne suína, desmitificando a imagem negativa agregada desde a sua produção até o consumo.

$\mathrm{O}$ baixo consumo pode estar ligadoà falta de incentivo ao consumo através de marketingque mostrem que exis- 
tem, no Brasil, as mais avançadas tecnologias e altos controles sanitários (FARIAS et al., 2012).

Figura 5: Visualização de propaganda de incentivo ao consumo de carne suína segundo os entrevistados em Colônia do Piauí-PI.

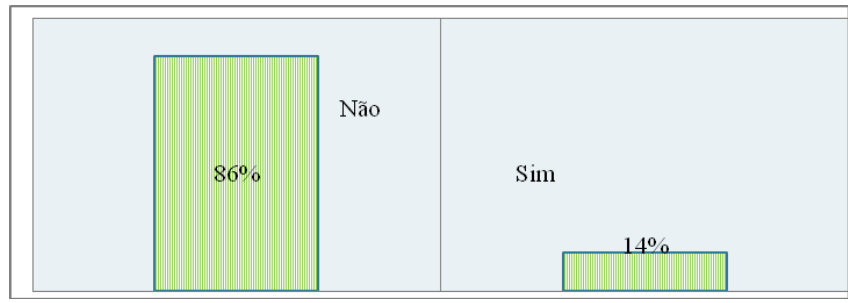

Como ilustra a (Figura 6), 95\% dos entrevistados consomem a carne suína. Resultados semelhantes foram encontrados por Silva, Santos e Pinheiro (2014) nas cidades de Porto Esperidião e Glória D’Oeste, $88 \%$ e 94\% respectivamente. Foi observado que o consumo da carne suína é bem popular, só não tem alta preferência e frequência, o que pode estar ligado aos mitos relacionados ao produto, este consumo pode até aumentar com esclarecimentos necessários, embasando nas questões principais, gordura e sanitárias.

A minoria dos entrevistados (5\%) afirmou não consumir a carne suína alegando fazer mal a saúde devido aos altos teores de gordura. Mas os mesmos deixaram claro que consomem os subprodutos dizendo fazer menos mal a saúde, por ser mais higiênico já vindo com todo um padrão de qualidade.

Pesquisas relacionadas ao consumo da carne suína afirmaram que a população brasileira considera como o principal ponto forte da carne suína o seu sabor apontado por $92 \%$ da população entrevistada. Mas, na mesma pesquisa ficou evidente que os pontos fracos foram de que "faz mal e é perigosa para a saúde" (35\% das respostas), e possuir "muita gordura e colesterol" (55\% das respostas) (SILVA; SILVA, 2009).

Farias et al. (2012) argumentaram que os avanços tecnológicos em suínos e a comunidade científica trabalham integralmente para melhorar a eficiência na produção de carne e atender as exigências crescentes do mercado consumidor.

Figura 6: Consumo da carne suína segundo os entrevistados em Colônia do Piauí-PI.

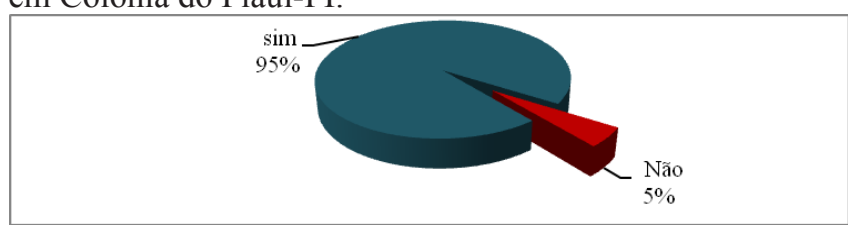

Dentre os que consomem carne suína, 34,74\% declararam consumir mensalmente, $26,32 \%$ quinzenalmente e apenas 2,1\% consomem diariamente (Figura 7), corroborando com resultados encontrados por Santos et al. (2011) e Nantes et al. (2014). Já pesquisa realizada por Santos et al. (2012) teve resultados parecidos no consumo diário em Rio Largo-AL que foi de apenas 2,96\%.

Com base nos dados acima se percebe que ainda há um baixo percentual no consumo diário da carne suína não só na região pesquisada, mas em outras regiões brasileiras. Um ponto muito comentado foi a quantidade de gordura presente na carne, vários consumidores afirmaram que desejavam que a carne suína fosse mais magra para que pudessem consumi-la com maior frequência.

Figura 7: Frequência do consumo da carne suína segundo os entrevistados em Colônia do Piauí-PI.

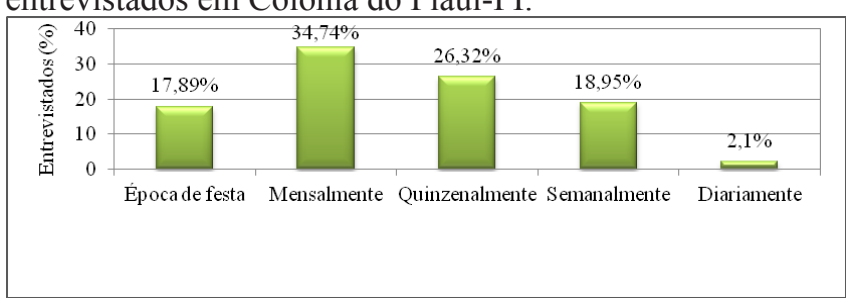

A renda familiar influenciou pouco no consumo de carne suína, sendo que o consumo mensal e quinzenal são os mais citados na faixa de renda de um a dois salários mínimos. Os aspectos relacionados ao consumo de proteínas cárneas não estão correlacionados com as classes socioeconômica das famílias, pois com o aumento da renda, a frequência de consumo não se elevou (Figura 8).

Figura 8: Renda familiar comparado com a frequência de consumo da carne suína pelos entrevistados em Colônia do Piauí-PI

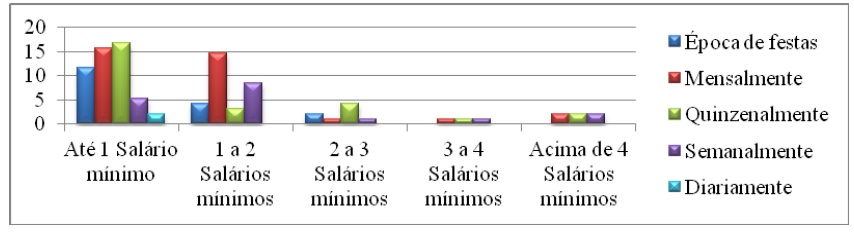

Observou-se que o grau de escolaridade interfere no consumo da carne suína, pois quando o grau de escolaridade aumentou a frequência de consumo diminuiu (Figura 9).

Figura 9: Frequência de consumo de carne suína relacionado ao grau de escolaridade pelos entrevistados em Colônia do Piauí-PI.

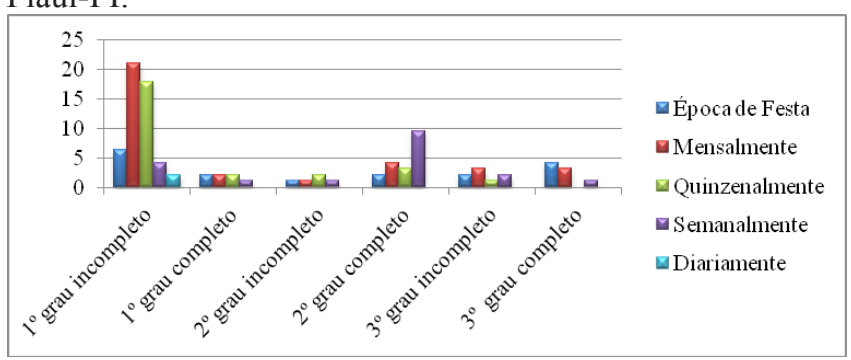

Quanto à forma de preparo, 92,63\% preferem a carne suína frita, 4,21\% cozida e 3,16\% assada (Figura 10). As pessoas não consomem a carne suína com maior frequência por ser uma carne gordurosa, favorecendo o surgimento de doenças, essencialmente causadas por má alimentação e falta de atividade física (GUEDES, 2012). O modo de preparar essa carne é uma questão de rotina, cultura, hábito e de consumo, alegando eles que torna o sabor da carne menos enjoativa (SILVA et al., 2012). 
Figura 10: Modo de preparo da carne suína para o consumo pelos entrevistados em Colônia do Piauí-PI.

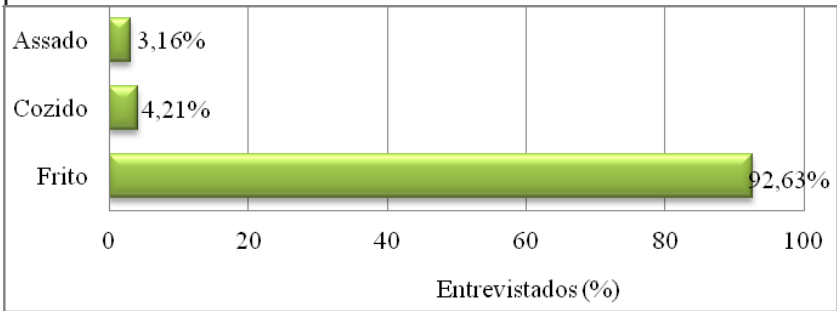

As principais razões apontadas como fatores para não consumir carne suína in natura foram: preocupação com teor de gordura presente na carne considerado por $55,8 \%$ dos consumidores e 17,9\% disse não encontrar a carne suína. Além desses motivos também foram mencionados: questões sanitárias sendo prejudicial à saúde por ser uma carne reimosa e também para mudar o sabor para variar ocardápio (Figura 11).

Foi possível observar que a população se preocupa mais com a quantidade de gordura e questões sanitárias, no que possa ser prejudicial a sua saúde, do que com o preço. Isso demostra que o preço não é o responsável pela baixa frequência do consumo da carne, mas a falta de informação sobre o teor de gordura e a higiene do produto, reduz bastante o consumo na região, pois a carne suína no município possui preço mais acessível do que a carne bovina.

Figura 11: Motivo para não consumir carne suína com maior frequência pelos entrevistados em Colônia do Piauí-PI.

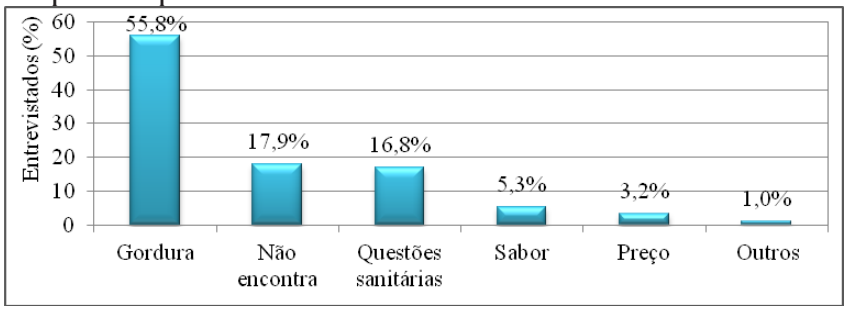

Quanto à forma de consumo, 77\% priorizam mais a carne in natura em relação à industrializada. Apesar dos consumidores ainda conceituarem a carne in natura como gordurosa e "forte" a maioria da população consome desta forma (Figura 12). Além do consumo em Colônia do Piauí-PI ser de forma natural, Machado et al. (2014) afirmam que o consumo Nordestino também é maior em forma in natura.

Figura 12: Consumo da carne suína industrializada e in natura pelos entrevistados em Colônia do Piauí-PI

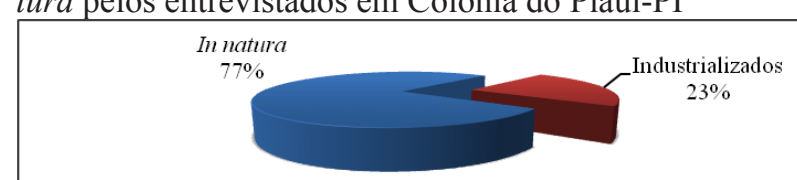

Dos subprodutos apresentados, à linguiça lidera com 48\% (Figura13). Silva \& Silva (2009) verificaram resultados semelhantes, dentre os industrializados a preferência na opinião do consumidor até mesmo pela praticidade e higienedos produtos sendo a linguiça citada por $43 \%$ dos entrevistados.
Figura 13: Nível de preferência por industrializados de carne suína pelos entrevistados em Colônia do Piauí-PI.

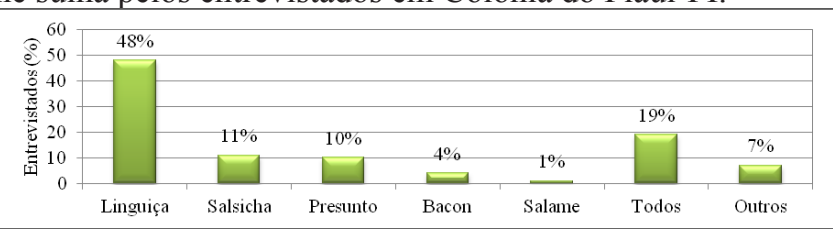

Dos cortes comerciais, a costela é a mais popular entre os consumidores, com $35,8 \%$, seguida pela bisteca com $34,7 \%$ (Figura 14). Corroborando com os resultados de Nantes et al. (2014) onde costela é a favorita para os consumidores com $16,1 \%$.

Cortes suínos e derivados, mais consumidos podem variar dependendo da região do país. Segundo Silva, Santos e Pinheiro, (2014) em Porto Esperidião os consumidores entrevistados preferem comprar bisteca, costela e lombo (53\%) em Glória D'Oeste, a maior parte dos entrevistados costuma comprar pernil e bisteca (71\%).

A preferência por esses dois cortes pode esta ligada a maior oferta de ambos, oferecidas em supermercados, vindo de outras regiões que disponibilizam cortes padronizados. Na cidade, a carne é comercializada sem divisões de cortes, sendo que todos os cortes apresentam o mesmo preço. A escolha por esses cortes pode está relacionada à facilidade $\mathrm{e}$ praticidade de preparo, onde a costela e a bisteca são cortes geralmente consumidos assados ou fritos.

Figura 14: Cortes cárneos suínos mais apreciados pelos entrevistados em Colônia do Piauí-PI.

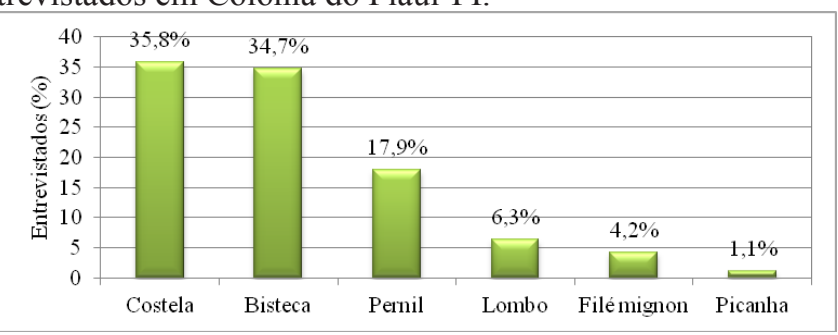

Verifica-se que mesmo se os médicos recomendassem e garantissem os benefícios que a carne suína pudesse trazer a maioria $(55,8 \%)$, não aumentaria o consumo (Figura 15). Antonangelo et al. (2011) observaram que $60 \%$ das pessoas entrevistadas responderam que, caso seu médico assegurasse a qualidade da carne suína, aumentariam seu consumo.

Essa opinião pode esta relacionada aos mitos de que a composição da carne possui alto teor de gordura e colesterol.

Figura 15: Aumento do consumo da carne suína por garantia médica pelos entrevistados em Colônia do Piauí-PI.

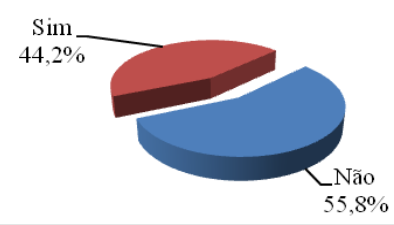

Os consumidores foram indagados quanto à importância dos aspectos gerais da carne suína considerados no momento da compra, mediante uma escala de 1 a 5 sendo 
o 1 considerado "sem importância" e o 5 "indiferente", aos aspectos de preço, marca, registro de inspeção federal, data de validade, composição nutricional, teor de gordura, corte e embalagem (Tabela 1).

Tabela 1: Ordem de importância dos aspectos gerais considerados no momento da compra da carne suína pelos entrevistados em Colônia do Piauí-PI.

${ }^{1}$ Registro de Inspeção Federal; ${ }^{2}$ Data de Validade; ${ }^{3}$ Composição Nutricional; ${ }^{4}$ Teor de Gordura

A data de validade foi o item considerado importante por $65,3 \%$ dos consumidores, e como muito importante por $30,5 \%$, totalizando $95,8 \%$ dos entrevistados, sendo o atributo de maior importância, indagando ser essencial conter a data de validade na embalagem, demonstrando as preocupações do consumidor em relação à qualidade do produto.

$\mathrm{O}$ teor de gordura foi o segundo item mais citado como importante ou muito importante por $92,5 \%$ dos entrevistados. É um item que o consumidor leva muito em consideração no momento da compra, pensando na saúde, visto que tanto as pessoas idosas como as jovens, preocupam-se em adquirir carnes com baixo teor de gordura.

O terceiro item mais importante foi a composição nutricional com $85,3 \%$, embora este item não seja possível observar a "olho nu", os consumidores disseram ser importante constar na embalagem para que haja toda uma confiança no momento de aquisição do produto. Antonangelo et al. (2011) também constaram em sua pesquisa, que a maioria dos consumidores de carne suína desconhece as características nutricionais da mesma.

A embalagem foi considerada o quarto item mais importante no momento da compra por $85,2 \%$ (Tabela 1 ). A embalagem deve ser transparente para a percepção das qualidades sensoriais da carne, além de conter informações necessárias sobre as características nutricionais, visto que os consumidores se preocupam com a higiene e limpeza, pois a carne bem embalada mostra a segurança do produto (SILVA; SILVA, 2009). Mesmos que as carnes comercializadas em Colônia do Piauí-PI não sejam embaladas adequadamente os entrevistados consideram a embalagem um item importante.

A marca ocupou o quinto lugar na ordem de importância com $82,1 \%$ dos consumidores, sendo a escolha por determinada marca associada à qualidade. $\mathrm{O}$ principal critério de escolha do consumidor é a aparência do produto, sendo que os consumidores dão preferência aos derivados com melhor marca comercial.

O registro de inspeção federal (RIF) e os cortes foram considerados importantes pelos entrevistados. Em Colônia do Piauí-PI as carcaças não passam por nenhum tipo de fiscalização, mesmo assim, os entrevistados julgaram importante estes atributos no momento da compra. A pouca demanda por carne suína na cidade pode estar associada à falta de cortes cárneos.

O preço foi mencionado por $50,5 \%$ dos entrevistados, como item importante (Tabela 1). Dessa forma, o preço não é o responsável pela baixa frequência do consumo da carne suína, visto que os entrevistados preocupam-se mais com a qualidade da carne dando maior ênfase por um produto com embalagem e todos os padrões de higiene. Os re- sultados encontrados no presente trabalho, estão de acordo com o relatado por Taffarel et al. (2013) os quais colocam que o preço nem sempre é um requisito de maior importância durante a aquisição de carne suína.

No quesito local de aquisição da carne suína in natura na região de Colônia do Piauí-PI, a maioria dos consumidores 47,4\% compra em açougue (Figura 16). Assemelhando-se aos resultados de Simões et al. (2012) os quais apontaram que $48 \%$ dos consumidores realizam a compra da carne suína em açougues em Aquidauana-MS.

A maioria dos entrevistados compram a carne suína em açougues por falta de opções, as condições higiênicas são precárias, em contato diretamente com microrganismos do ambiente e dos objetos, sem nenhum tipo de refrigeração, quando há diminuição do fluxo de pessoas comprando, no final do dia a carne vai ao freezer.

Figura 16: Local de aquisição da carne suína pelos entrevistados em Colônia do Piauí-PI.

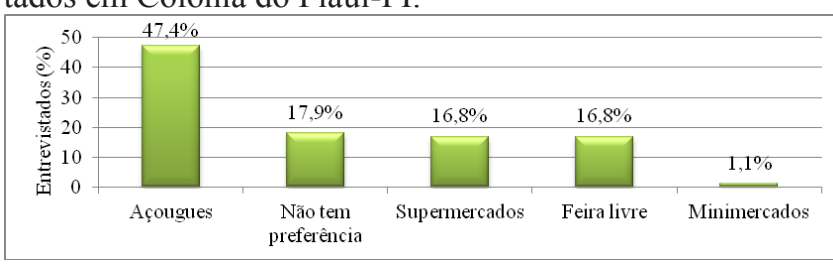

\section{Conclusões}

O principal entrave para consumo da carne suína pode estar atrelado à falta de esclarecimento sobre os benefícios que a carne suína pode trazer, e de investimentos em marketing que desmistifiquem os problemas relacionados às questões sanitárias e ao teor de gordura. A frequência de consumo pode ser aumentada, já que o preço não foi o fator limitante para o consumo.

\section{Referências}

ANTONANGELO, A. et al. Perfil dos consumidores de carne suína no município de Botucatu - SP. Tékhne \& Lógos, v. 2, n. 2, 2011.

BAPTISTA, R. I. A.; BERTANI, G. R.; BARBOSA, C. N. Indicadores do bem-estar em suínos. Ciência Rural, v. 41, n. 10, p. 1823-1830, 2011.

BERTOL, T. M. et al. Qualidade da carne e desempenho de genótipos de suínos alimentados com dois níveis de aminoácidos. Pesquisa Agropecuária Brasileira, v. 6, n. 45, p. 621-629, 2010.

FARIAS, A. E. M. de. et al. Estudo socioeconômico dos consumidores de carne suína em três municípios do sertão paraibano.Acta Veterinária Brasílica, v. 6, n. 3, p. 199 203,2012

GUEDES, V. L. Teias ecológicas consumo de carne e de calorias. Educação Ambiental em Ação. n. 41, 2012. Disponível em: $<$ http://www.revistaea.org/artigo. php?idartigo $=1302>$. Acesso em: 01 jun 2017. 
HAUTRIVE, T. P.; MARQUES, A. C.; KUBOTA, E. H. Avaliação da composição centesimal, colesterol e perfil de ácidos graxos de cortes cárneos comerciais de avestruz, suíno, bovino e frango. Alimentos e Nutrição, v. 23, n. 2, p. 327-334, 2012.

\section{INSTITUTO BRASILEIRO DE GEOGRAFIA E} ESTATÍSTICA. IBGE. Indicadores IBGE: Produção pecuária municipal. Brasil, v.41, p.1-108, 2013. Disponível em: <http://www.ibge.gov.br>. Acesso em: 13 fev. 2015.

MACHADO, S. T. et al. Impactos da renda familiar e do preço no consumo da carne suína. Enciclopédia biosfera, Centro Científico Conhecer, v. 10, n. 18, p. 1912-1928, 2014.

MUNIZ, D. C. et al. Caracterização do consumo de carne suína e avícola "in natura" através dos estabelecimentos comerciais no município de Ilhéus-Bahia. Revista

Eletrônica de Pesquisa Animal, v. 3, n. 1, p. 24-34, 2015.

NANTES, C. L. et al. Profile and preference of pork consumers in Campo Grande - MS. Revista Agrarian, v. 7, n. 25 , p. 460-467, 2014.

RAINERI, C. et al. Contribution to economic evaluation of systems that value animal welfare at farm. Revista Colombiana de Ciências Pecuárias, v. 2, n. 1225, p. 123134, 2012.

SALES, L. E. M. de. et al. Avaliação da carne suína in naturacomercializada em Mossoró-RN. Acta Veterinária Brasílica, v. 7, n. 4, p. 306-310, 2013.

SANTOS, E. L. et al. Mercado consumidor de carne suína e seus derivados em Rio Largo - AL. Acta Veterinária Brasílica,v. 6, n. 3, p. 230-238, 2012.

SANTOS, T. M. B. et al. Diagnóstico do perfil do consumidor de carne suína no município de AquidauanaMS. Revista Brasileira de Saúde e Produção Animal, v. 12, n. 1, p. 1-13, 2011.

SILVA, J. P. da; SILVA, L. P. G. da. Estudo e avaliação do consumidor de carne suína "in natura" e industrializada na microrregião de Guarabira - PB. ACSA-Agropecuária Científica no Semiárido, v. 5, p. 57-61, 2009.

SILVA, M. R.; SANTOS, M. O.; PINHEIRO, M. S. M. Perfil do consumo de carne suína nos municípios de Glória d'oeste e Porto Esperidião. Revista ACSA, v. 10, n. 2, p. 35-41, 2014.

SILVA, R. A. M. et al. Associação de ractopamina e vitaminas antioxidantes para suínos em terminação. Ciência Rural, v. 45, n. 2, p. 311-316, 2015.

SIMÕES, A. R. P. et al. Aspectos da comercialização da carne suína no varejo no município de Aquidauana-MS, Revista Agraria, v. 5, n. 18, p. 417-427, 2012.
SOUZA, G. S. et al. Previsões para o mercado de carnes. Revista de Economia e Sociologia Rural, v. 49, n. 2, p. 473-492, 2011.

TAFFAREL, T. R. et al. Mercado consumidor de carne suína e derivados no município de Lavras, Minas Gerais. Revista Eletrônica de Pesquisa Animal, v. 1, n. 1, p. 51$61,2013$.

THOMS, E. et al. Perfil de consumo e percepção da qualidade da carne suína por estudantes de nível médio da cidade de Irati, PR. Revista Acadêmica: Ciências Animal, v. 8, n. 4 , p. $449-459,2010$. 